\title{
URINARY PORPHYRIN EXCRETION IN NORMAL CHILDREN AND ADOLESCENTS
}

\author{
James S. Woods ${ }^{a}$, Michael D. Martin ${ }^{b}$, Brian G. Leroux ${ }^{c, d}$, Timothy A. DeRouen ${ }^{c}, d$, Mario F. \\ Bernardo $^{\mathrm{e}}$, Henrique S. Luis ${ }^{\mathrm{e}}$, Jorge G. Leitão ${ }^{\mathrm{e}}, 1$, P. Lynne Simmonds ${ }^{\mathrm{a}}$, and Tessa C. \\ Rue ${ }^{\text {, d }}$ \\ ${ }^{a}$ Department of Environmental and Occupational Health Sciences, University of Washington, \\ Seattle, Washington, USA \\ ${ }^{b}$ Department of Oral Medicine, University of Washington, Seattle, Washington, USA \\ 'Department of Dental Public Health Sciences, University of Washington, Seattle, Washington, USA \\ dDepartment of Biostatistics, University of Washington, Seattle, Washington, USA \\ eFaculdade de Medicina Dentaria, Universidade de Lisboa, Lisbon, Portugal.
}

\begin{abstract}
Background-Urinary porphyrins are diagnostic of various metabolic disorders and xenobiotic exposures, but comprehensive normative data for urinary porphyrin concentrations in children are currently unavailable.
\end{abstract}

\begin{abstract}
Methods-Subjects were participants in a prospective, randomized, controlled clinical trial of dental materials safety, 8 to $12 \mathrm{y}$ at inception, who were followed longitudinally for $7 \mathrm{y}$ after baseline with an extensive battery of neurobehavioral, neurological, renal function and urinary porphyrin assessments. Porphyrins were quantified by HPLC. Linear regression analyses were used to measure associations of porphyrin levels with age and gender.
\end{abstract}

Results-Mean concentrations, $95 \%$ confidence intervals, and $10^{\text {th }} 50^{\text {th }}$, and $90^{\text {th }}$ percentiles for all 5 typically excreted urinary porphyrins are presented by year of age and by gender. Unadjusted urinary concentrations $(\mu \mathrm{g} / \mathrm{l})$ of all 5 porphyrins remained relatively constant throughout the age range of $8-18$ y for both males and females. In contrast, creatinine-adjusted urinary porphyrin concentrations $(\mu \mathrm{g} / \mathrm{g})$ declined significantly throughout this age range in both genders. Boys had significantly higher pentacarboxyl- and copro- porphyrin levels compared with girls both before and after creatinine adjustment.

Conclusions-Normative longitudinal data provided herein may facilitate the clinical assessment of pediatric metabolic disorders and may be of particular relevance in evaluating porphyrin changes as a biological indicator of disease or xenobiotic exposures among children and adolescents.

\footnotetext{
(C) 2009 Elsevier B.V. All rights reserved.

Author to whom page proofs should be sent: James S. Woods, Ph.D., Department of Environmental and Occupational Health Sciences, University of Washington, 4225 Roosevelt Way NE, Suite 100, Seattle, WA 98105. Tel.: 206 685-3443; Fax: 206 685-4696, e-mail: Email: jwoods@u.washington.edu.

${ }^{1}$ Present address: Universidade Católica Portuguesa, Departamento das Ciências da Saúde, Lisbon, Portugal

Publisher's Disclaimer: This is a PDF file of an unedited manuscript that has been accepted for publication. As a service to our customers we are providing this early version of the manuscript. The manuscript will undergo copyediting, typesetting, and review of the resulting proof before it is published in its final citable form. Please note that during the production process errors may be discovered which could affect the content, and all legal disclaimers that apply to the journal pertain.
} 


\section{Keywords}

urine; porphyrins; children; adolescents

\section{INTRODUCTION}

Porphyrins are formed as intermediates in the biosynthesis of heme, a process that takes place in essentially all eukaryotic tissues. In humans and other mammals, porphyrins with 8,7,6,5, and 4 carboxylated side chains (uro-, heptacarboxyl-, hexacarboxyl-, pentacarboxyl-, and copro- porphryins) are commonly formed in excess of that required for heme synthesis and are excreted in the urine and/or feces in established concentration ranges [1,2]. Urinary porphyrin excretion may be abnormally elevated in a number of disease states including the inherited porphyrias [3,4], certain liver and kidney diseases [5,6], and disorders of hemoglobin synthesis [7]. Abnormal porphyrin excretion has also been documented in response to a variety of drugs [8] and environmental chemical exposures, particularly, organochlorine compounds $[9,10]$ and heavy metals such as lead [11], arsenic [12,13], and mercury [14,15]. In each case, the specific changes in porphyrin excretion patterns are potentially useful as diagnostic indicators of ensuing, existing or remitting disease or chemical toxicity [16-19].

The efficacy of altered urinary porphyrin concentrations and excretion patterns as biomarkers of disease or toxicant exposure is contingent upon the availability of established normal reference values, which can vary by both age and gender. Whereas urinary porphyrin concentrations are well established for adult human subjects $[1,2,15]$, normative values of urinary porphyrins for developmentally healthy children and adolescents are not available.

\section{MATERIALS AND METHODS}

\section{The Study Population}

The children's cohort was derived from the recently completed Casa Pia clinical trial of the health effects of dental amalgam fillings in children [20]. Subjects $(n=507)$ were boys and girls (54:46\%), 70\% white, aged 8-12 y at inception, who were residents of the Casa Pia school system in Lisbon, Portugal. All subjects who participated in the clinical trial from which the data reported herein were recruited were residents of the same boarding school throughout all years of the trial. As such, they received the same diet and were comparable in all other social respects. Eligibility requirements precluded children with preexisting neurological or developmental disabilities, dental amalgam tooth fillings or blood lead levels $\geq 10$ ( $\mu \mathrm{g} / \mathrm{dl}$. Subjects were initially randomized to mercury amalgam (treatment) or composite resin (control) dental treatment groups. Because amalgam treatment is suspected to impact urinary porphyrin profiles [21], only subjects receiving composite resin fillings (controls, $n=254$ ) were included in the present assessment of normative porphyrin levels. Children were evaluated at baseline and at 7 subsequent annual intervals after initial dental treatment with an extensive battery of neurobehavioral, neurological, renal function and urinary porphyrin assessments. Follow-up data were obtained on a similar number of subjects in each treatment group. The study protocol was approved by the institutional review boards at the University of Washington and the University of Lisbon. All parents or guardians gave written consent, and all children provided signed assent. Principal design and analytical issues involved in this trial [22] as well as principal outcome measures [20] have been reported.

\section{Procedures for urine collection and measurement of urinary porphyrins and creatinine}

A urine sample $(\sim 50 \mathrm{ml})$ was collected from each child at baseline and at each subsequently scheduled annual visit to the University of Lisbon School of Dental Medicine for dental, 
neurological and neurobehavioral evaluations. Immediately following urine collection, a 10 $\mathrm{ml}$ aliquot was removed and acidified with $1 \mathrm{~mol} / \mathrm{l} \mathrm{HCl}$ for use in mercury analysis by continuous flow, cold vapor spectrofluorometry [23]. Porphyrins were quantified in the remaining unacidified portion of the urine sample by high performance liquid chromatography, as previously described [24]. Urinary creatinine concentrations were also measured in unacidified urine using a standard colorimetric procedure (Sigma, St. Louis, MO).

\section{Statistical analyses}

We used separate linear regression models for each porphyrin to test whether gender and age were associated with average urinary porphyrin concentration $(\mu \mathrm{g} / \mathrm{l})$ during the study among the composite group. We also tested for age and gender associations with average creatinine adjusted urinary porphyrin levels $(\mu \mathrm{g} / \mathrm{g})$. We tested for age effects separately for each gender. Robust standard errors were used to account for possible within-child correlation and heteroskedasticity (variances increased with increasing mean value).

\section{RESULTS}

Table 1 presents demographic characteristics at baseline (BL) and at each year of follow-up for all subjects in the composite (control) group for whom porphyrin assay results were available. Subjects at baseline ranged in age from 8 to $12 \mathrm{y}$, mean $10 \mathrm{y}$. Table 2 presents distributions $\left(10^{\text {th }}, 50^{\text {th }}, 90^{\text {th }}\right.$ percentiles $)$, mean values, and $95 \%$ confidence intervals for the mean values of unadjusted concentrations $(\mu \mathrm{g} / \mathrm{l})$ of individual and total urinary porphyrins by gender and age for children from ages $8-18 \mathrm{y}$. As shown, unadjusted porphyrin concentrations remain relatively constant throughout the age range of 8 to $18 \mathrm{y}$ for both genders. Notably, however, boys have significantly $(\mathrm{p}<0.05)$ higher unadjusted pentacarboxyl- and coproporphyrin concentrations than girls throughout this age range.

Table 3 presents distributions $\left(10^{\text {th }}, 50^{\text {th }}, 90^{\text {th }}\right.$ percentiles $)$, mean values, and $95 \%$ confidence intervals for mean values of creatinine-adjusted concentrations $(\mu \mathrm{g} / \mathrm{g})$ of individual and total urinary porphyrins by gender and age for children from ages 8-18 y. As shown, creatinineadjusted porphyrin concentrations decline significantly $(\mathrm{p}<0.0001)$ throughout this age range in both genders. Boys again were seen to have significantly $(\mathrm{p}<0.05)$ higher creatinine-adjusted pentacarboxyl- and copro- porphyrin levels compared with girls. Additionally, blacks were found to have significantly lower creatinine-adjusted (but not unadjusted) urinary porphyrin levels than whites at all ages. This finding is attributed to significantly higher creatinine excretion among blacks [25].

Table 4 presents individual porphyrin concentrations as a percentage of total porphyrins for each age and gender. Va lues represent the percent of total urinary porphyrin concentration for each individual porphyrin. Table 5 presents mean creatinine concentrations $(\mathrm{g} / \mathrm{l})$ for each age and gender. Values increased by a comparable amount in both boys and girls over the age range of 8 to $15 \mathrm{y}$, then become relatively stable throughout the remaining $3 \mathrm{y}$ of follow up to age 18 $\mathrm{y}$. No significant differences in creatinine excretion between boys and girls were found. A comprehensive report of longitudinal creatinine excretion values [25] in this subject population is published.

\section{DISCUSSION}

An important data gap exists for normative urinary porphyrin concentrations for children and adolescents. Bloom et al. [26] described total urinary porphyrin and creatinine values as functions of age and sex among children aged from 9 months to $18 \mathrm{y}$. These observations are of limited diagnostic value, however, since urinary concentrations for individual porphyrins were not provided. More recently, Sunyer et al. [10] employed linear regression analysis to 
evaluate potential changes in urinary porphyrin excretion in relation to organochlorine compound exposure among 4 y-old children. However, no normative values for urinary porphyrin levels for children of this age were reported. In other studies, Ahmed [27] described biochemical abnormalities in childhood porphyrias, but no normative urinary porphyrin data were provided. Age-dependent reference values for urinary porphyrins among children aged from 0.5 to 15 y were reported by Minder et al. [28]; however, these assessments were restricted only to uro- and copro- porphyrin levels. Isomers of individual porphyrins, which may be of importance in the evaluation of certain diseases or disorders, were not evaluated in the present study.

Of note from the present findings is the observation that total urinary porphyrin concentrations are higher in pre-adolescent children of both sexes and decline to reported adult ranges [1,2, 15,29 ] only by the late teen years. Although absolute concentrations of coproporphyrin appear to contribute most substantially to higher porphyrin levels observed in younger children (Table 2 and Table 3), it is notable that the proportion of total porphyrin attributable to coproporphyrin increases somewhat from ages 8 through $18 \mathrm{y}$, whereas the proportion of total porphyrin attributable to uroporphyrin decreases by as much as 2 -fold over this age range (Table 4 ). These findings accentuate the importance of evaluating porphyrin alterations in children in relation to mean porphyrin values for healthy children of the same age, rather than in relation to adult reference values. Also of note is the observation that boys had significantly higher unadjusted urinary concentrations of pentacarboxyl- and copro- porphyrins than girls throughout much of the 8-18 age range. This difference was retained following creatinine adjustment (Table 3), consistent with finding that urinary creatinine levels did not differ significantly between males and females throughout the course of the study (Table 5). Similar finding were reported by Bloom et al. [26], in which total creatinine-adjusted urinary porphyrin concentrations in boys aged 9-18 y were higher than those seen in similarly aged girls. The mechanisms and possible biological significance of this gender distinction remain to be determined. Notably, sex hormones have been reported to influence porphyrin metabolism [30], possibly accounting for this difference.

Also of considerable importance from the present findings is the importance of creatinine adjustment when evaluating porphyrin changes among children of any age, owing to the significant increase in creatinine excretion that occurs throughout late childhood and adolescence. In the present population, urinary creatinine excretion increased over 2-fold from $0.68 \mathrm{~g} / \mathrm{l}$ to $1.44 \mathrm{~g} / \mathrm{l}$ between ages 8 and $18 \mathrm{y}$. These findings are of particular relevance when evaluating porphyrin changes as a biological indicator of disease or disorder among younger children, whose creatinine-adjusted porphyrin levels are likely to differ significantly from those of teen-aged subjects or adults. For comparisons of children of similar age, creatinineadjustment offers the additional advantage in facilitating interpretation of porphyrin changes in random ("spot") or incompletely collected 24-h urine samples from children who are unable to provide complete $24-\mathrm{h}$ urine specimens.

In conclusion, this study provides comprehensive normative values for urinary concentrations and ranges for 5 typically excreted porphyrins in healthy children between the ages of 8 and $18 \mathrm{y}$. These data may facilitate the clinical assessment of pediatric metabolic disorders and may be of particular relevance in evaluating porphyrin changes as a biological indicator of disease or xenobiotic exposure among children and adolescents.

\section{ACKNOWLEDGEMENTS}

This research was funded by Cooperative Agreement U01DE11894 from the National Institute of Dental and Craniofacial Research (NIDCR), National Institutes of Health (NIH). Additional funding was provided by Center Grant P30ES07033 to the University of Washington from the National Institute of Environmental Health Sciences (NIEHS), NIH. The study protocol employed in the trial was approved by the institutional review boards at the 
University of Washington and the University of Lisbon. All parents or guardians gave written consent, and all children provided written assent.

\section{REFERENCES}

1. Ford RE, Ou C-N, Ellefson RD. Liquid-chromatographic analysis for urinary porphyrins. Clin Chem 1981;27:397-401. [PubMed: 7471387]

2. Woods JS, Martin MD, Leroux BG. Validity of spot urine samples as a surrogate measure of 24-hour porphyrin excretion rates. J Occup Environ Med 1998;40:1090-1101. [PubMed: 9871886]

3. Poh-Fitzpatrick MB, Ramsay CA, Frain-Bell W, et al. Photodermatosis in infants and children. Pediatr Dermatol 1988;5:189-200. [PubMed: 3205860]

4. Poh-Fitzpatrick MB. Laboratory testing in the porphyrias. Int J Dermatol 1979;18:452-460.

5. Ostrowski J, Kosecki P, Martynska M, et al. Urinary porphyrins in liver disease. Scand J Gastroenterol 1984;19:862-866. [PubMed: 6515322]

6. Day S, Eales L. Porphyrins in chronic renal failure. Nephron 1980;26:90-95. [PubMed: 6997766]

7. Lyberatos M, Papadopoulos N, Papasteriadis E, et al. Urine porphyrins and their precursors in homozygous $\beta$-thalassaemia. Acta Haematol 1975;54:95-97. [PubMed: 808946]

8. Moore, MR.; McColl, KEL.; Rimington, C.; Goldberg, A. Chapter 5: Drugs, Chemicals, and Porphyria. In: Moore, MR., et al., editors. Disorders of Porphyrin Metabolism. New York and London: Plenum Press; 1987.

9. Goldstein JA, Hickman P, Jue DL. Experimental hepatic porphyria induced by polychlorinated biphenyls. Toxicol Appl Pharmacol 1974;27:443-448.

10. Sunyer J, Alvarez-Pedrerol M, To-Figueras J, Rabas-Fito N, et al. Urinary porphyrin excretion in children is associated with exposure to organochlorine compounds. Environ Health Perspect 2008;116:1407-1410. [PubMed: 18941586]

11. Sassa, S. Toxic effects of lead, with particular reference to porphryin and heme metabolism. In: DeMatteis, F.; Aldridge, WN., editors. Handbook of Experimental Pharmacology: Heme and Hemoproteins. Vol. 44. New York, NY: Springer-Verlag; 1978. p. 333-371.

12. Ng JC, Qi L, Moore MR. Porphyrin profiles in blood and urine as biomarker for exposure to various arsenic species. Cell Molec Biol 2002;48:111-123. [PubMed: 11929043]

13. Garcia-Vargas GC, Del Razo LM, Cebrian ME, Albores A, et al. Altered urinary porphyrin excretion in a human population chronically exposure to arsenic in Mexico. Hum Exper Toxicol 1994;13:839_ 847. [PubMed: 7718303]

14. Bowers MA, Aicher LD, Davis AH, Woods JS. Quantitative determination of porphyrins in rat and human urine and evaluation of urinary porphyrin profiles during mercury and lead exposures. J Lab Clin Med 1992;120:272-281. [PubMed: 1500825]

15. Woods JS, Martin MD, Naleway CA, Echeverria D. Urinary porphyrin profiles as a biomarker of mercury exposure: Studies in dentists with occupational exposure to mercury vapor. J Toxicol Environ Health 1993;40:235-246. [PubMed: 8230299]

16. Badminton MN, Elder GH. Molecular mechanisms of dominant expression in porphyria. J Inherit Metab Dis 2005;28:277-286. [PubMed: 15868463]

17. Anderson KE, Bloomer JR, Bonkovsky HL, Kushner JP, et al. Recommendations for the diagnosis and treatment of the acute porphyrias. Ann Intern Med 2005;142:439-450. [PubMed: 15767622]

18. Daniell WE, Stockbridge HL, Labbe RF, Woods JS, et al. Environmental chemical exposures and disturbances of heme synthesis. Environ Health Perspect 1997;105:37-53. [PubMed: 9114276]

19. Woods, JS. Porphyrin metabolism as indicator of metal exposure and toxicity. In: Goyer, RA.; Cherian, MG., editors. Handbook of Experimental Pharmacology: Toxicology of MetalsBiochemical Aspects. Vol. 115. New York, NY: Springer-Verlag; 1995. p. 19-25.

20. DeRouen TA, Martin MD, Leroux BG, Townes BD, et al. Neurobehavioral effects of dental amalgam in children. A randomized clinical trial. J Am Med Assoc 2006;295(15):1784-1792.

21. Woods JS, Martin MD, Leroux BG, DeRouen TA, et al. Urinary porphryin excretion in children with mercury amalgam treatment: Findings from the Casa Pia children's dental amalgam trial. J Toxicol Environ Health. 2009(in press) 
22. DeRouen TA, Leroux BG, Martin MD, Townes BD, et al. Issues in the design and analysis of a randomized clinical trial to assess the safety of dental amalgam restorations in children. Contr Clin Trials 2002;23:301-320.

23. Pingree SD, Simmonds PL, Woods JS. Effects of 2,3-dimercapto-1-propanesulfonic acid (DMPS) on tissue and urine mercury levels following prolonged methyl mercury exposure in rats. Toxicol Sci 2001;61:224-233. [PubMed: 11353131]

24. Woods JS, Bowers MA, Davis HD. Urinary porphyrin profiles as biomarkers of trace metal exposure and toxicity: Studies on urinary porphyrin excretion patterns in rats during prolonged exposure to methyl mercury. Toxicol Appl Pharmacol 1991;110:464-476. [PubMed: 1949014]

25. Martin MD, Woods JS, Leroux BG, Rue T, et al. Longitudinal urinary creatinine excretion values among preadolescents and adolescents. Trans Res 2008;151:51-56.

26. Bloom KE, Zaider EF, Morledge LJ, Poh-Fitzpatrick MB. Urinary porphryin excretion I normal children and adults. Am J Kidney Dis 1991;14:483-489. [PubMed: 1928067]

27. Ahmed I. Childhood porphyrias. Mayo Clin Proc 2002;77:825-836. [PubMed: 12173716]

28. Minder EI, Schneider-Yin X. Age-dependent reference values of urinary porphyrins in children. Eur J Clin Chem Clin Biochem 1996;34:439-443. [PubMed: 8790980]

29. Bonkovsky HL, Siao P, Roig Z, Hedley-Whyte ET, Flotte TJ. Case 20-2008: A 57 year-old woman with abdominal pain and weakness after gastric bypass surgery. New Engl J Med 2008;358:28132825. [PubMed: 18579817]

30. Tschudy, DP. The influence of hormonal and nutritional factors on the regulation of liver heme biosynthesis. In: DeMatteis, F.; Aldridge, WN., editors. Handbook of Experimental Pharmacology: Heme and Hemoproteins. Vol. 44. New York, NY: Springer-Verlag; 1978. p. 255-271. 


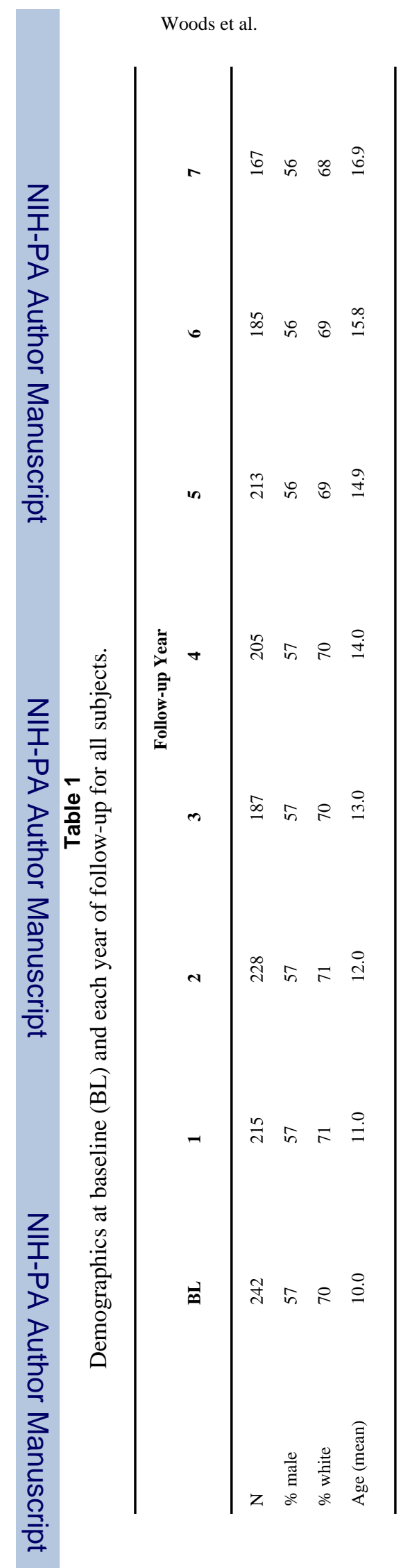

Clin Chim Acta. Author manuscript; available in PMC 2010 July 1. 


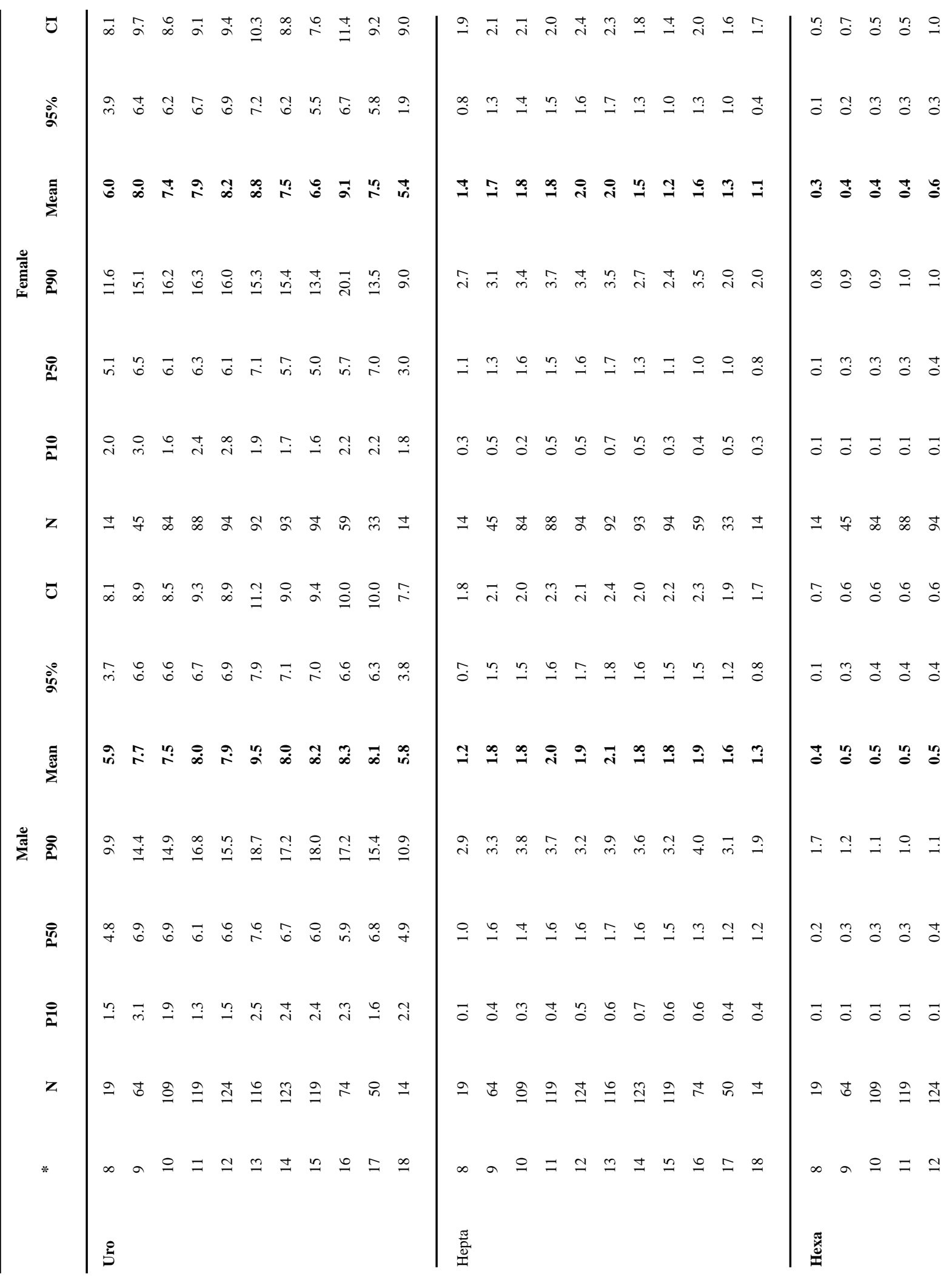




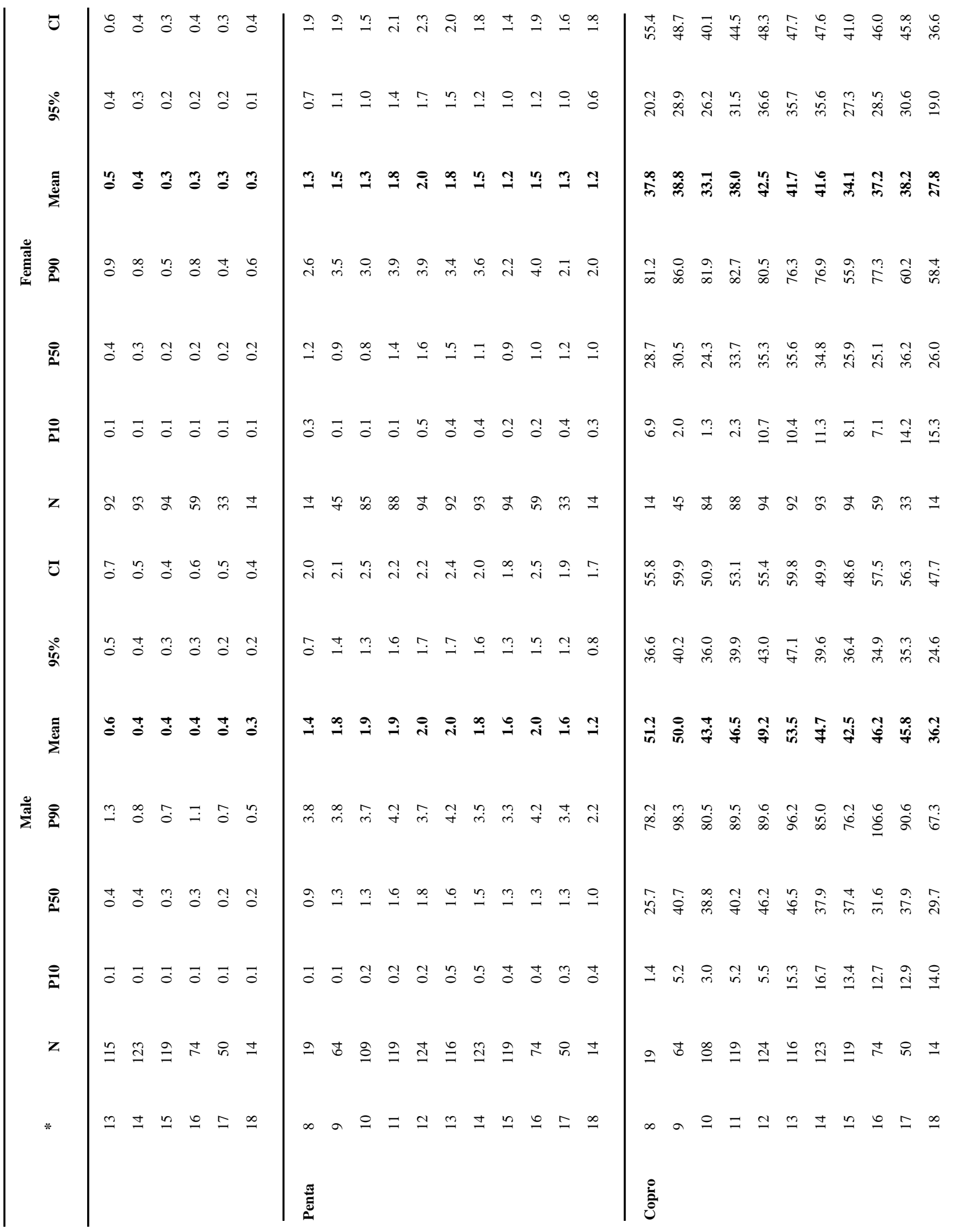




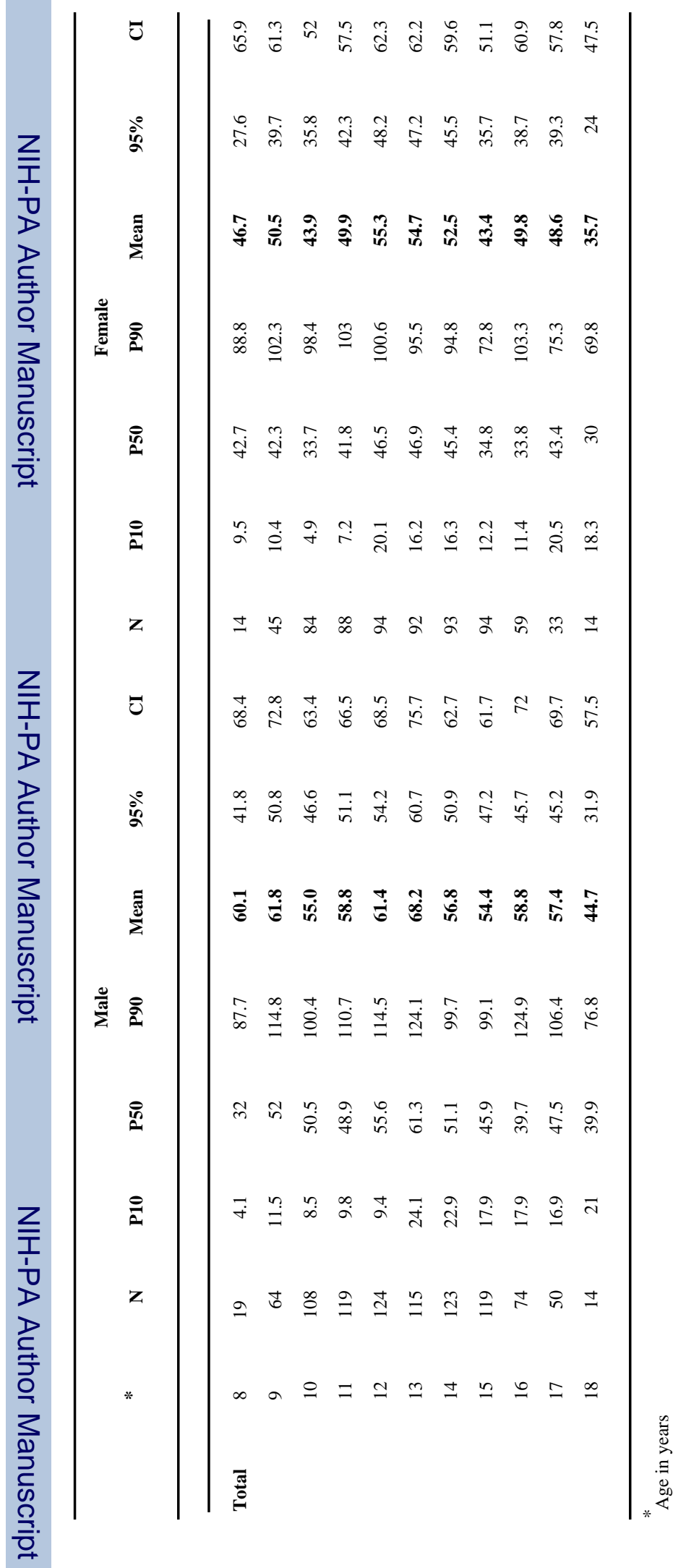

Clin Chim Acta. Author manuscript; available in PMC 2010 July 1. 


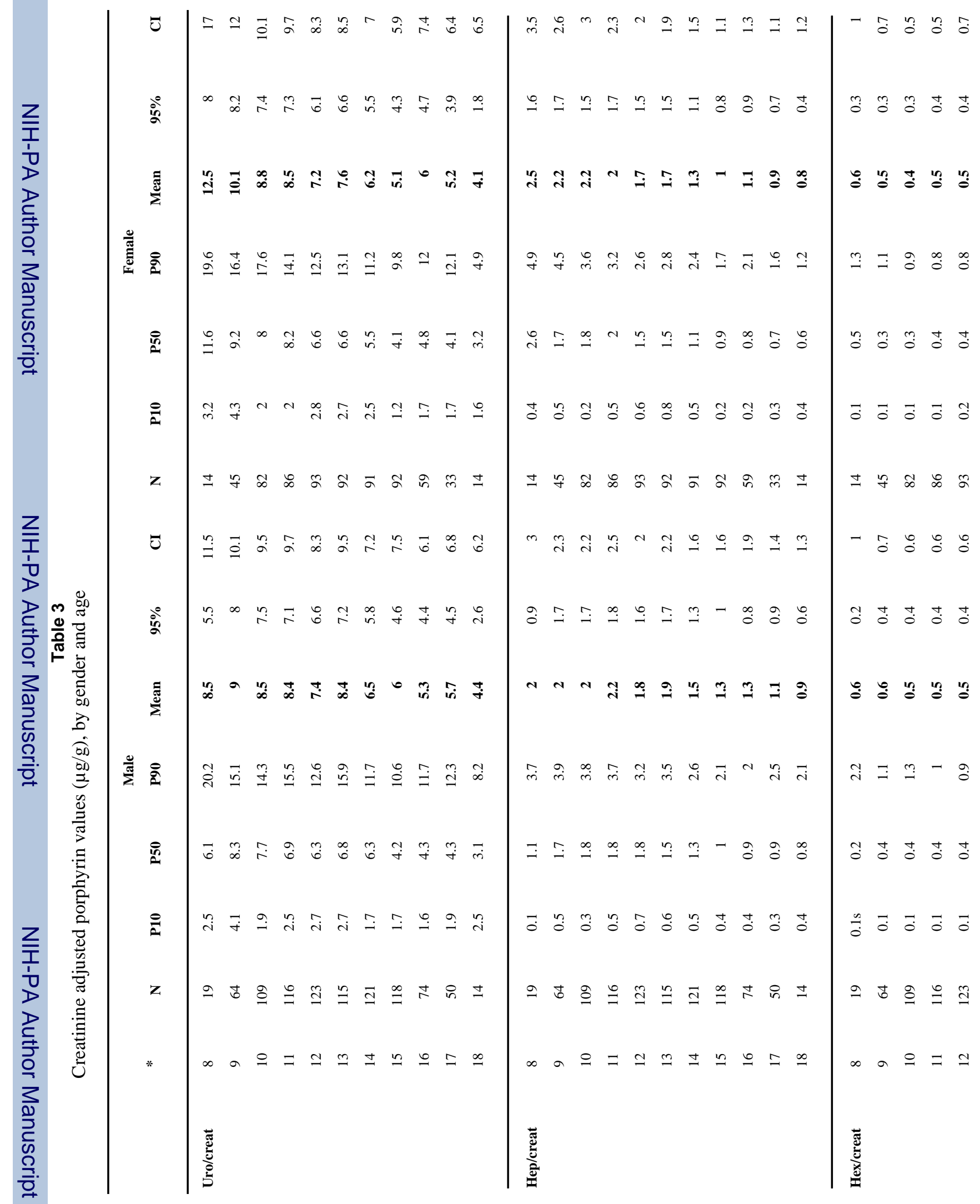




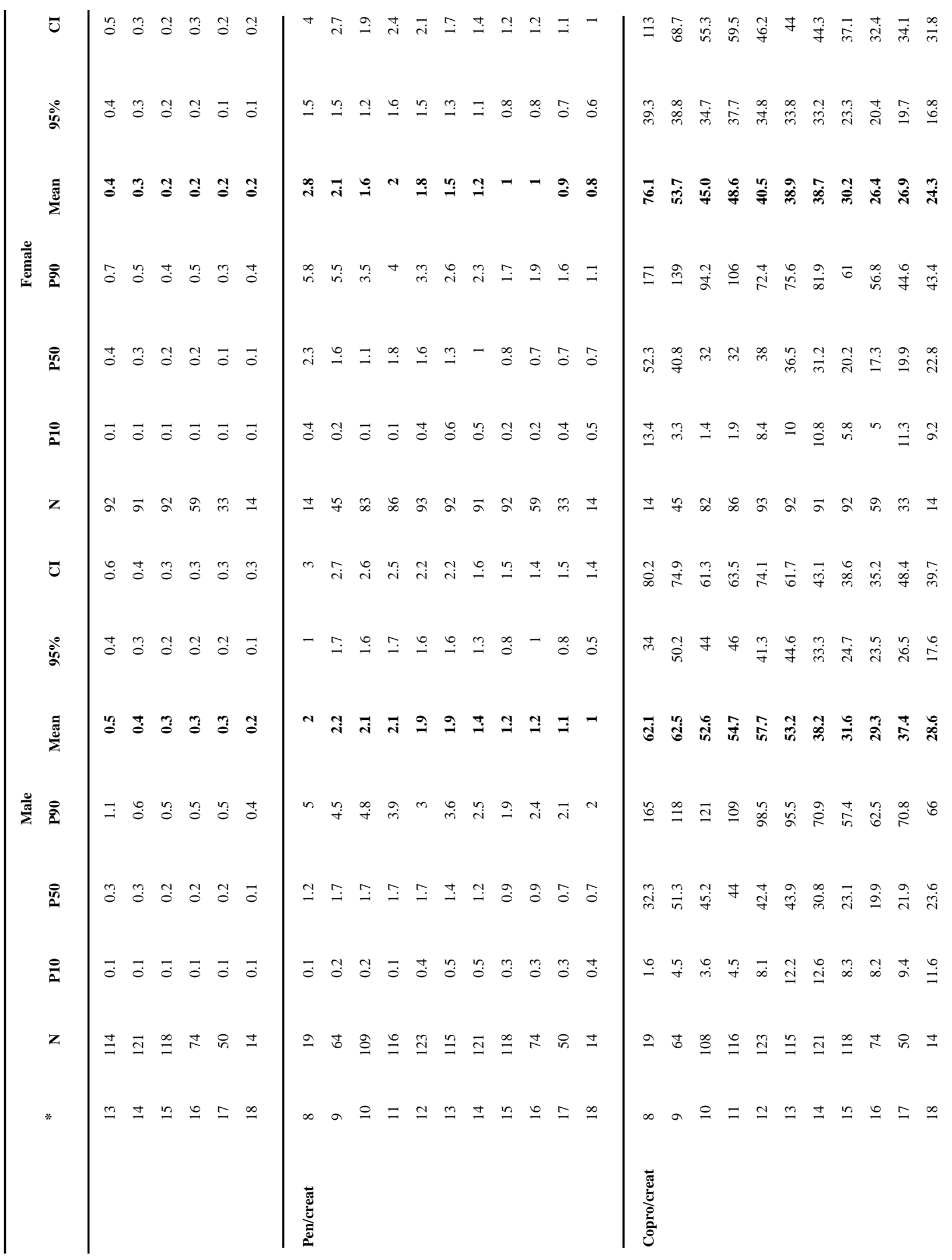




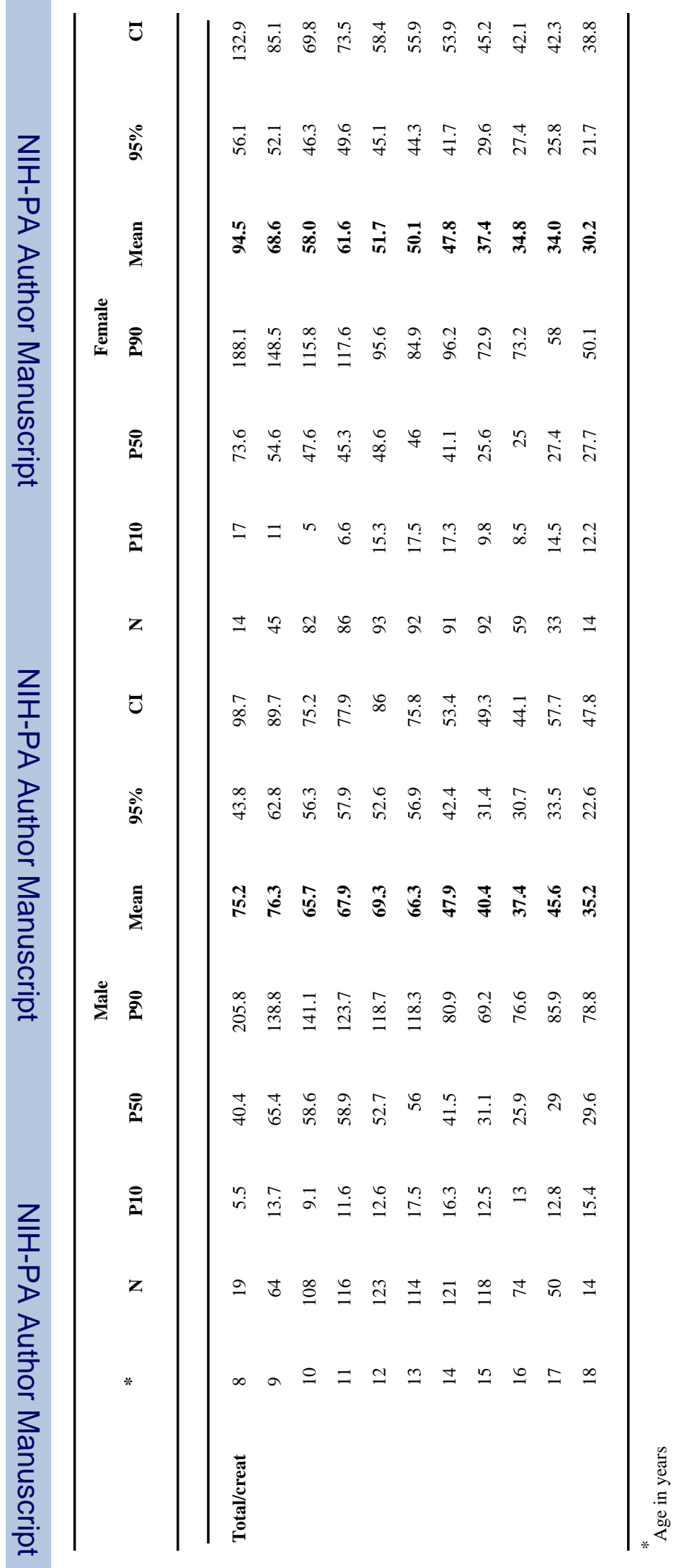

Clin Chim Acta. Author manuscript; available in PMC 2010 July 1. 


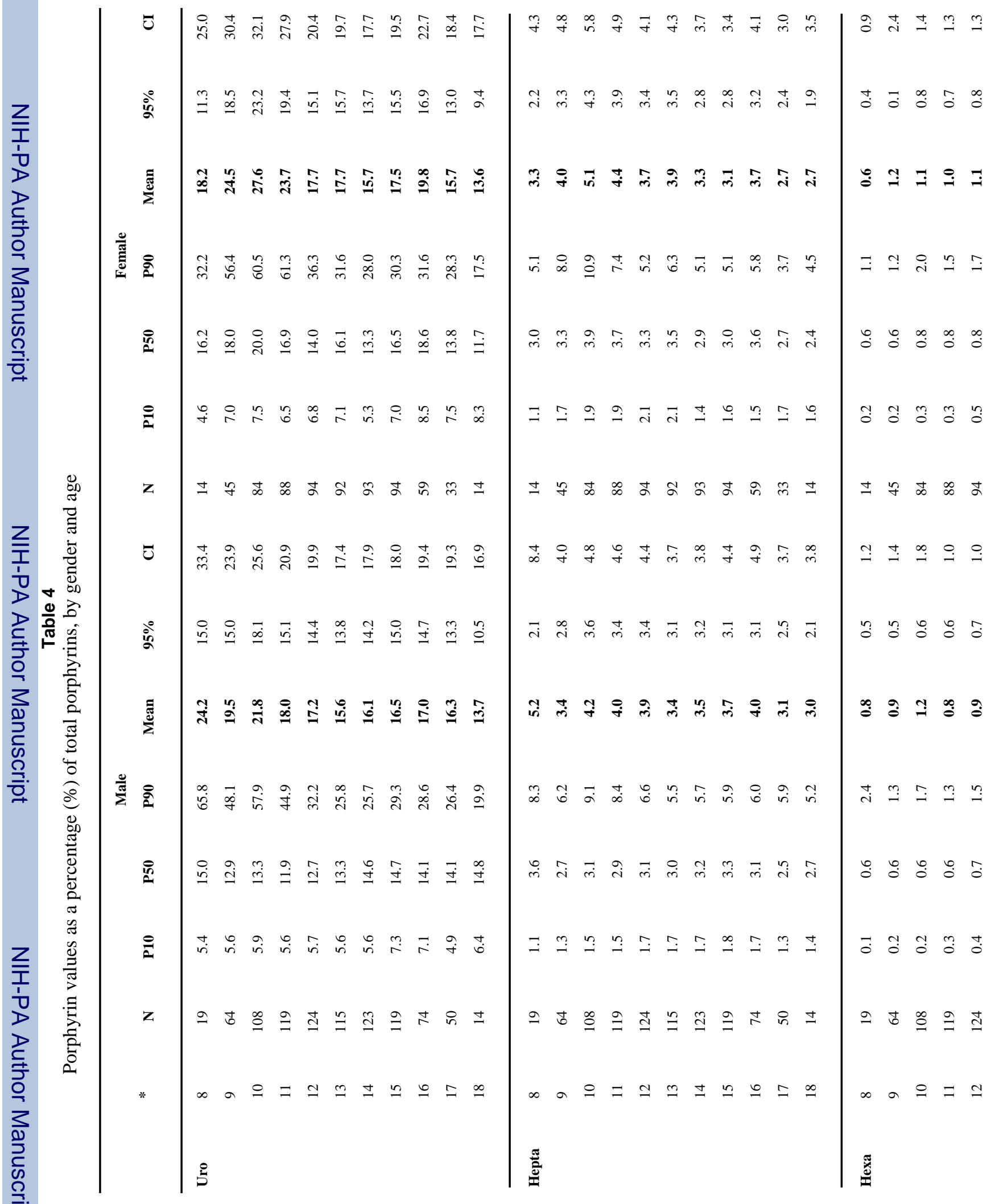




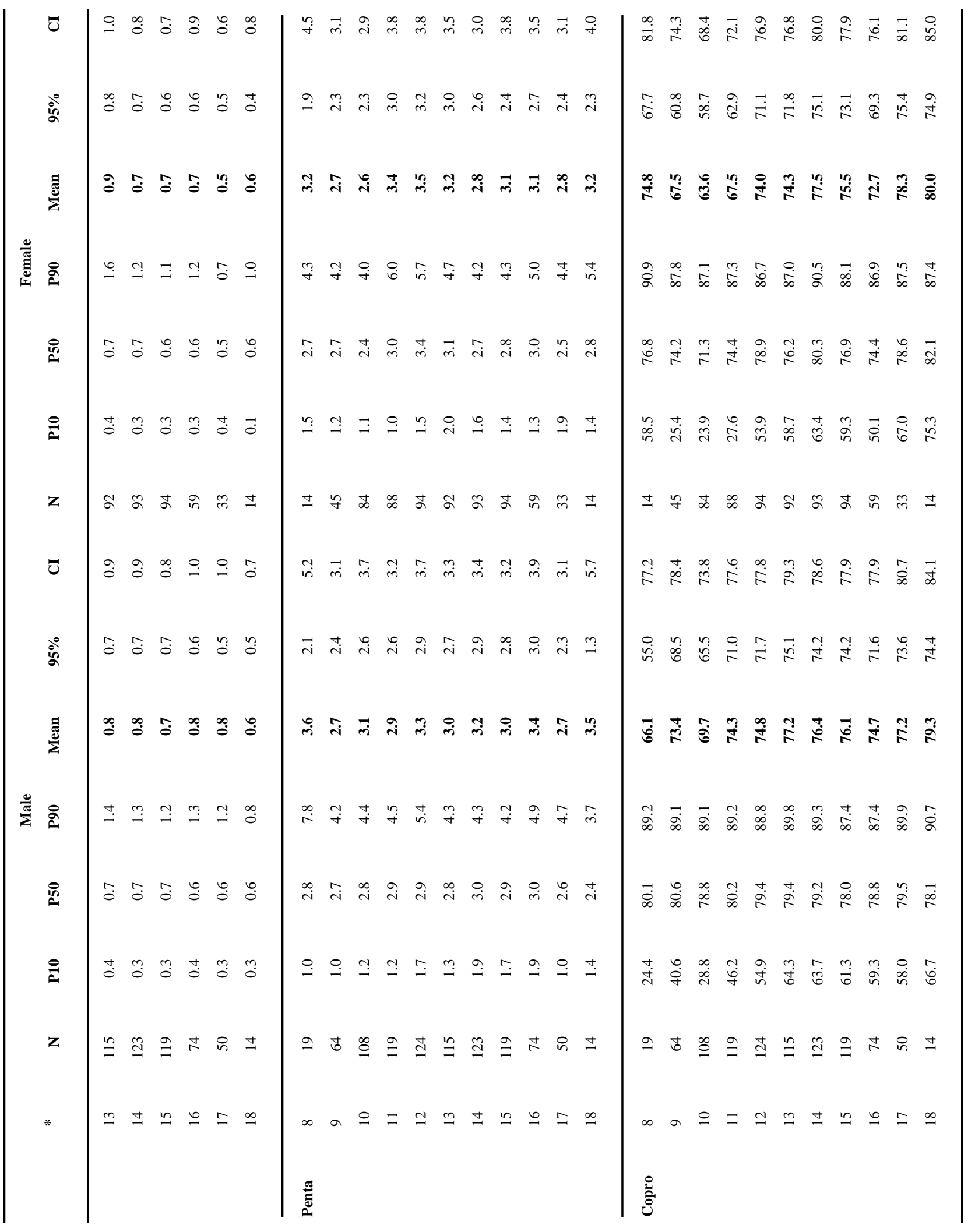




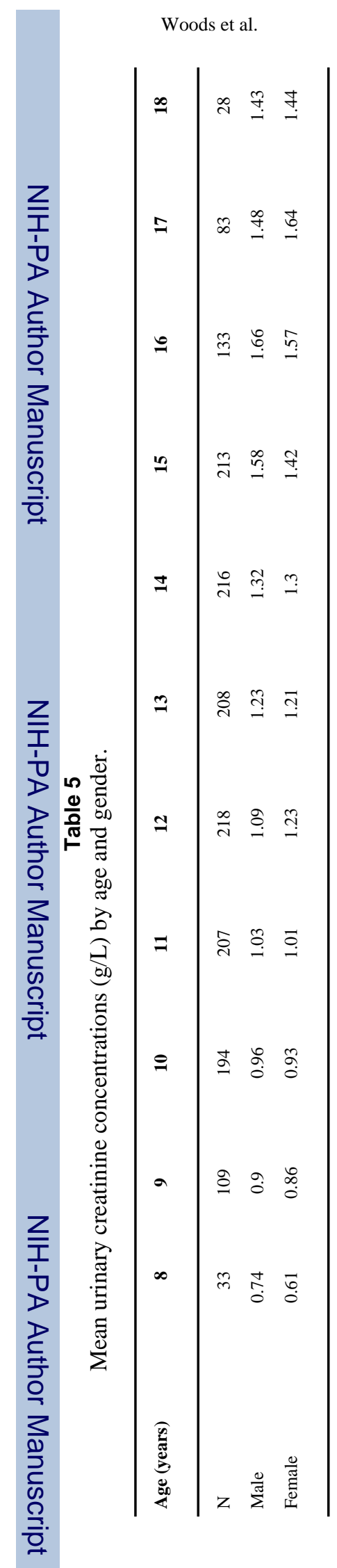

Page 17 